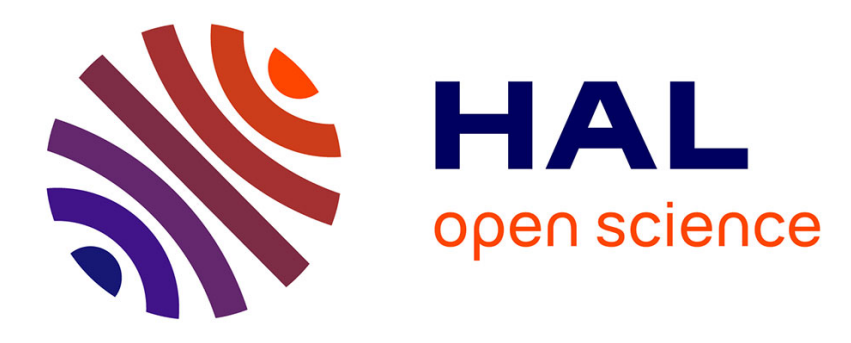

\title{
Modeling of humps formation during deep-penetration laser welding
}

El Hachemi Amara, Rémy Fabbro

\section{To cite this version:}

El Hachemi Amara, Rémy Fabbro. Modeling of humps formation during deep-penetration laser welding. Applied physics. A, Materials science \& processing, 2010, 101, pp.111-116. 10.1007/s00339-0105768-z . hal-00915605

\section{HAL Id: hal-00915605 https://hal.science/hal-00915605}

Submitted on 9 Dec 2013

HAL is a multi-disciplinary open access archive for the deposit and dissemination of scientific research documents, whether they are published or not. The documents may come from teaching and research institutions in France or abroad, or from public or private research centers.
L'archive ouverte pluridisciplinaire HAL, est destinée au dépôt et à la diffusion de documents scientifiques de niveau recherche, publiés ou non, émanant des établissements d'enseignement et de recherche français ou étrangers, des laboratoires publics ou privés. 


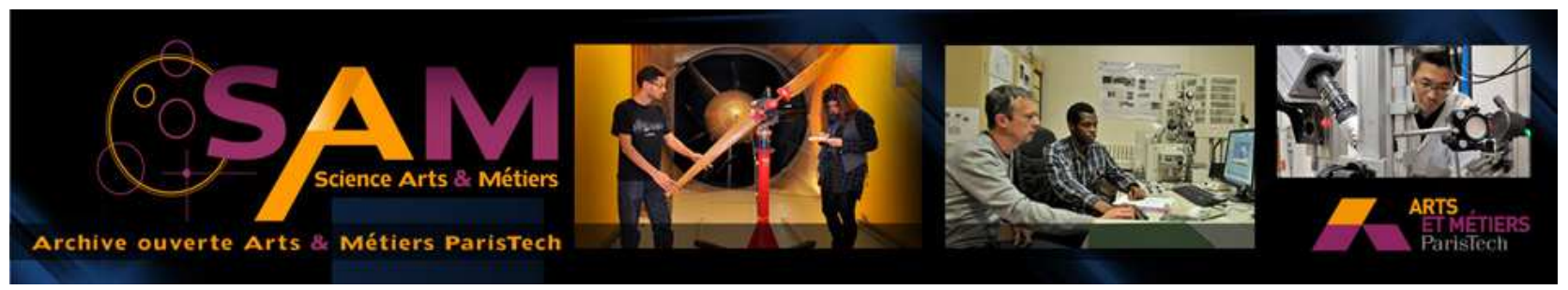

Science Arts \& Métiers (SAM)

is an open access repository that collects the work of Arts et Métiers ParisTech researchers and makes it freely available over the web where possible.

This is an author-deposited version published in: http://sam.ensam.eu

Handle ID: .http://hdl.handle.net/10985/7615

\section{To cite this version :}

El Hachemi AMARA, Rémy FABBRO - Modeling of humps formation during deep-penetration laser welding - Applied Physics A : Materials Science and Processing - Vol. 101, p.111-116 2010 


\title{
Modeling of humps formation during deep-penetration laser welding
}

\author{
E.H. Amara · R. Fabbro
}

\begin{abstract}
A 3-D transient modeling based on the numerical resolution of the fluid flow ant the heat transfer equations is developed for deep-penetration laser welding at highwelding speed regime, which results in the humping phenomenon. The physical mechanisms included in our model concern matter melting, vaporization inducing a recoil pressure, and resolidification. The implementation of developed procedures called User Defined Functions (UDFs) working interactively with the CFD Fluent code and a dynamic mesh method allowed us to treat the problem with specific and complex boundary conditions. The recoil pressure, fusion, resolidification, and the temperature dependence of the physical properties were thus taken into account. As a result, regular humps could be observed after resolidification on the weld seam.
\end{abstract}

\section{Introduction}

Fast laser welding by deep penetration is an advanced joining process which nowadays is of growing interest due to economical and automation integration issues. It was observed that when the processing speeds are ranging from 12 to $19 \mathrm{~m} / \mathrm{min}$, an elongated keyhole is obtained and the surface of the melt pool shows rather small fluctuations. At higher velocities, above $20 \mathrm{~m} / \mathrm{min}$, the humping regime is reached, it results in weld seams with a periodic occurrence of beadlike protuberances, and very strong undercuts, composed of large swellings of quite ellipsoidal shape, separated by smaller valleys $[1,2]$. This defect constitutes a major inconvenience to move towards high-velocity welding. Various theoretical approaches were proposed to understand humps formation [3], and experimental data were compiled to verify the models related to welding by different processes [4]. However, we have found that few models on simulation of the humping phenomenon have been proposed, and the very interesting one concerns the simulation of humping occurrence in arc welding, performed by Cho [5, 6], where the Flow3D CFD packages was used, with the implementation of the Volume Of Fluid method (VOF) for interface tracking. In our contribution, we propose a 3-D transient modeling of deep-penetration welding at high processing speed, based on the numerical resolution of the fluid flow and the heat transfer equations with suitable boundary conditions. The involved physical processes associated with the laser-matter interaction are a very complex phenomenon to understand from basic principles, due to the simultaneous occurrence of solid, liquid, gas and plasma states in a small volume. Many physical mechanisms occur since the first stage of the laser interaction with matter, leading to laser energy absorption. The melting of the material surface, its vaporization, the phase interactions, the interaction with the laser beam and the resolidification processes determine the weld-joint pattern and its quality. The physical phenomena such as matter removing, once the absorbed laser energy is beyond the material vaporization threshold, the movement of the melt pool at the surface, the free surface deformation, the solid-liquid interface evolution, the resolidification are involved in our modeling. The govern- 
Fig. 1 The sample at $t=0$, and during the welding process
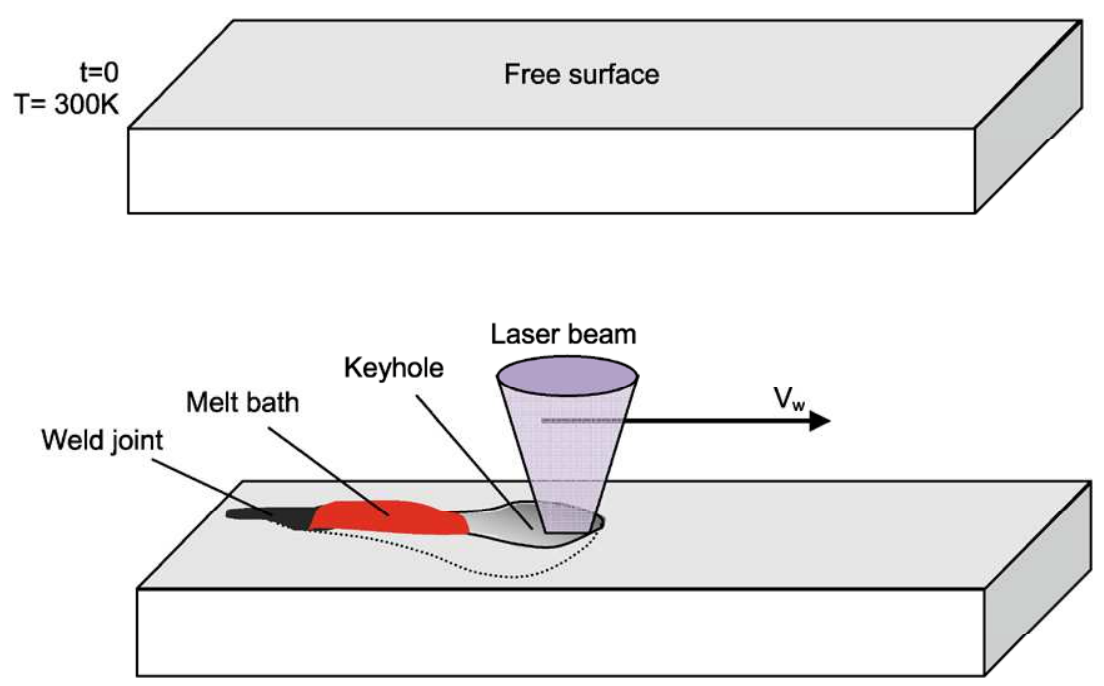

ing equations were solved numerically by finite-volume discretization implemented by Fluent CFD code [7], and in order to involve the complex specific boundary conditions, the physical mechanisms and the temperature dependent physical properties, we developed procedures called user-defined functions (UDFs), which were used interactively with Fluent solver. We have considered in our UDFs the recoil pressure, which is among the physical mechanisms responsible for the free surface deformation. The interest in free surface deformation, induced by high-power laser beams, goes up again to the end of seventies and early eighties. A pioneering work has been reported by Tribel'skii [8] in 1978, who determined theoretically the shape of the free surface of the melt undergoing deformations due to the recoil pressure. In 1980, Bunkin et al. reviewed [9] the various aspects on the interaction of high-power optical radiation with a liquid. In 1981, they studied the melt surface shape variation as a function of the laser beam velocity [10], and in 1983 Samokhin [11] investigated the influence of evaporation on the melt behavior during laser interaction with metal. Due to the great economical challenge of high-velocity laser welding, the investigations on deep-penetration laser welding still capture great interest, and as a contribution, learning on our previous work [12], the free surface deformation resulting in keyhole and humps formation is studied using dynamic mesh and enthalpic approaches. The results obtained show the occurrence of humps after resolidification.

\section{Modeling}

\subsection{Surface deformation and liquid movement}

A multiphase problem involving cavity formation and inducing liquid movements in the presence of solid material is considered. The involved physical mechanisms are the

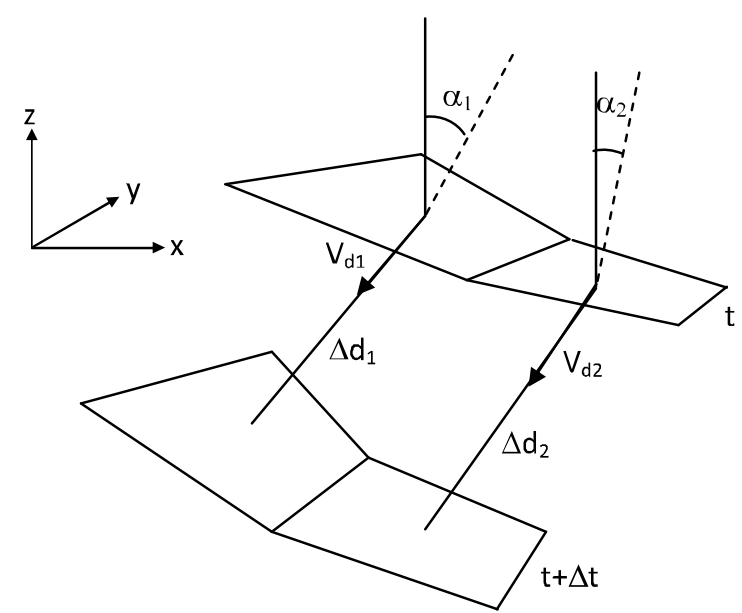

Fig. 2 Effect of the drilling velocity on surface elements

local laser energy absorption, the induced melting and vaporization, and then the resolidification. We assume that the sample surface was flat at the initial time $t=0$, and that the whole sample temperature was at $T=300 \mathrm{~K}$, as shown in Fig. 1a, while the different regions representing the melt bath, the keyhole and the weld joint during the welding process, are sketched in Fig. 1b.

Firstly we simulate the surface deformation under the laser beam effect by considering the local drilling velocity described by Semak et al. [13], when the deposited laser absorbed energy is beyond the material vaporization threshold. The surface displacement produced by the drilling velocity is given by

$$
\Delta d=v_{d} \Delta t
$$

Fabbro et al. [14] have proposed this approach in a 2-D model for the calculation of keyhole profiles. We have applied this approach in a 3-D calculation by considering the 


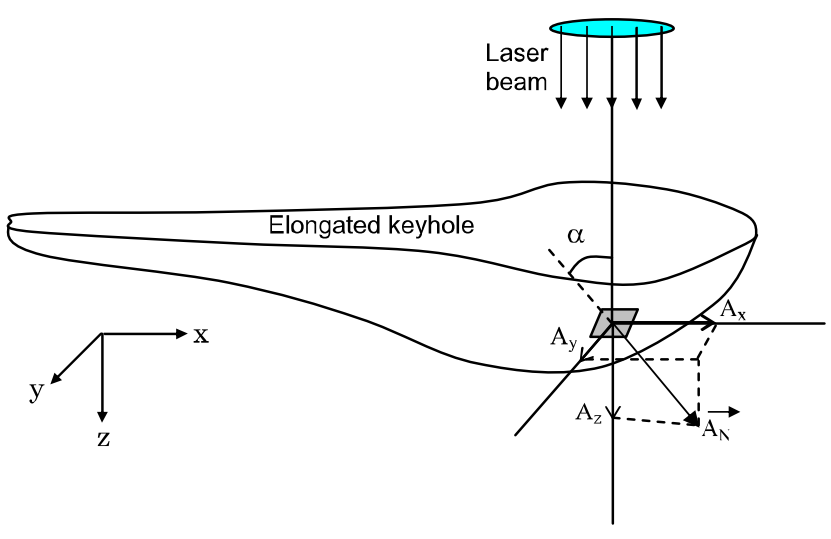

Fig. 3 3-D schematic representation of the keyhole, and a surface element, with its normal vector

normal vectors on surface elements. As an illustration, Fig. 2 shows two surface elements of the sample, where the laser beam impinges under different angles relatively to the surface elements orientations. The absorbed laser energy induces a drilling velocity, which results in a movement of the elements over a distance $\Delta d_{i}$ during the time step $\Delta t$.

The drilling velocity is proportional to the absorbed laser intensity following the relation:

$v_{d}=K I_{\mathrm{abs}} \cos (a)$

where $K$ is a proportionality factor, $I_{\text {abs }}$ the absorbed laser intensity, and a the beam incidence angle over the sample surface. The local absorbed laser intensity is thus needed in order to calculate the free surface deformation, it is required also the knowledge of the local incident angle $\alpha$ of the laser beam over the surface element.

We proceed by considering the surface pattern as a 3-D envelope where we need to know the normal vector $\vec{A}_{N}$ at each surface element as shown in Fig. 3, where $A_{x}, A_{y}$ and $A_{z}$ represent the vector components. The modulus of the normal vector $\vec{A}_{N}$ and also the vector components are data reachable from Fluent, which update the mesh geometry after each time step. Thus one can obtain the incidence angle $\alpha$ through the relation:

$\cos (a)=A_{z} /\left|\vec{A}_{N}\right|$

and one can thus calculate the absorbed intensity such as (for a Gaussian beam):

$$
I_{\mathrm{abs}}=A\left(2 P / \pi r_{1}^{2}\right) \cos ^{1.2}(\alpha) \exp \left(-2 r^{2} / r_{1}^{2}\right)
$$

Where $A$ is the absorption coefficient of the material, related to the used laser wavelength, $P$ the laser power, and $r_{1}$ the beam focal spot radius.

In our approach, we consider that the laser beam moves over the free surface of the sample at a welding speed $v_{w}$. As shown on Fig. 4, the position $r$ is calculated such as

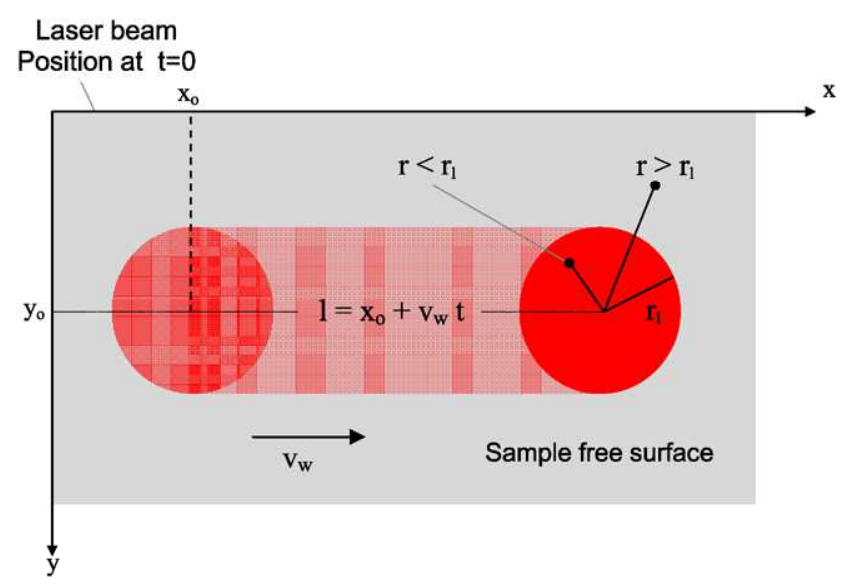

Fig. 4 Representation of the laser beam on the free surface

$r=\left[\left((1-x)^{2}+y^{2}\right)\right]^{1 / 2}$, where $1=x_{o}+v_{w} t$, with $x_{o}$ the initial position of the laser beam on the sample surface, and $v_{w}$ the translational laser beam displacement velocity. When $r<=r_{1}, I_{\text {abs }}$ is calculated following (4), else if $r>r_{1}$, then $I_{\text {abs }}$ is equal to zero. Thus, knowing the local absorbed laser intensity, at each surface element, we deduce the drilling velocity $v_{d}$, which is used to calculate surface elements displacements, and then the whole envelope deformation is obtained for the 3-D geometry.

The material melting and resolidification are calculated by an enthalpic method, and the surface tension variation due to the temperature difference produces a stress on the wall, which is taken into account in this modeling. This stress, called Marangoni stress, is given by $\tau=$ $(d \sigma / d T) \nabla_{s} T$, where $d \sigma / d T$ is the surface tension gradient and $\nabla_{s} T$ is the surface gradient. In the case of iron, we have taken $d \sigma / d T=-10^{4} \mathrm{~N} / \mathrm{m} / \mathrm{K}$ [15]. We have noticed that the inclusion of a surface tension effect through this gradient is of high importance for the observation of humps.

\subsection{Dependance of the physical properties on the temperature}

The density, the heat capacity and the heat conductivity of the treated material are considered to vary with the temperature. From Duley [16], we deduce the following expressions for the density and heat conductivity:

$$
\begin{aligned}
& \rho(T)=-0.4522 T+7755.7\left[\mathrm{~kg} / \mathrm{m}^{3}\right] \\
& k(T)=-0.0218 T+76.307[\mathrm{~W} / \mathrm{m} / \mathrm{K}]
\end{aligned}
$$

whereas, to take into account the latent heat effects on the temperature distribution, an increasing of the heat capacity given by Toyerskani et al. [17] is applied such as

$C_{p}^{*}(T)=\frac{1}{T_{m}-T_{a}}\left[L_{f}+\int_{T_{a}}^{T_{m}} C_{p} d T\right]$ 
Where $L_{f}$ is the material latent heat of fusion $\left(L_{f}=\right.$ $2.76 \times 10^{5} \mathrm{~J} / \mathrm{kg}$ for the iron), and $C_{p}^{*}$ the modified heat capacity. By developing the expression (5) for the iron, we obtain an approximation of the heat capacity $C_{p}^{*}[\mathrm{~J} / \mathrm{kg} / \mathrm{K}]$ as a function of the temperature such as:

$C_{p}^{*}(T)=2.6137 \times 10^{-4} T^{2}+0.12034621 T+124$

\section{Results and discussions}

In the present work, we have used the laser beam parameters given in Ref. [2], where the laser power was $4 \mathrm{~kW}$, the beam diameter was $600 \mu \mathrm{m}$ and the laser wavelength was $1.06 \mu \mathrm{m}$ (Nd_YAG laser). For an iron sample, submitted to a CW-Nd_YAG laser beam, the absorption coefficient A is 0.3 , and the proportionality coefficient $\mathrm{K}$ is taken equal to $3 \times 10^{-11}(\mathrm{~m} / \mathrm{s}) /\left(\mathrm{W} / \mathrm{m}^{2}\right)$.

The displacement velocity of the laser beam which we used in our modeling is $0.8 \mathrm{~m} / \mathrm{s}(\sim 50 \mathrm{~m} / \mathrm{min})$. An iron parallelepipedal sample with the dimensions: $15 \mathrm{~mm} \times 2 \mathrm{~mm}$ $\times 1 \mathrm{~mm}$, is considered, where the 3-D structured mesh is constituted of triangular cells on walls and tetrahedral cells inside the volume. The sample geometry, the domain meshing and the boundary reservation are performed by the pre-processor Gambit of Fluent softwares. Fluent solver is used to solve the corresponding Navier-Stokes equations by finite-volume discretizing. The boundary conditions and temperature dependant material properties are introduced by the mean of user-defined functions, or UDF, written in $\mathrm{C}$ programming language. These UDFs are used to customize Fluent and adapt it to a particular need required by the modeling. They can be used in various applications such as customizing boundary conditions or the definition of work-pieces physical properties depending on the temperature. They can be loaded interactively in the calculation procedure during the numerical resolution of the equations by the processor Fluent. This allows for enhancing the standard features of the calculation code. In this modeling, we have developed UDFs in order to introduce the operating conditions, the different involved physical mechanisms such as laser energy deposition and recoil pressure, and the specific boundary conditions related to our problem.

The performed study was relatively complex since to make evident the humping phenomenon, we had to use a 3-D approach, and also to take into account the keyhole formation since the initial instant $t=0$, when the laser beam drops onto the material surface. The laser energy deposited over the surface, leads to a deformation process due to the matter vaporization while the laser beam moves on the free surface at the processing speed $v_{w}$. The dynamic mesh was difficult to stabilize, and many configurations have been tested before finding the suitable mesh. Indeed, when the boundary
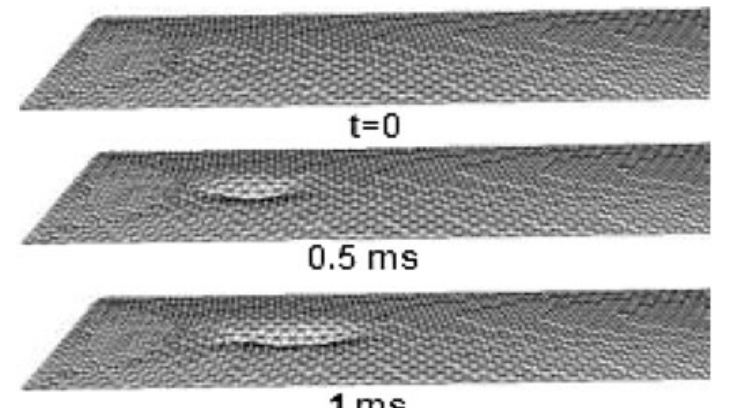

$1 \mathrm{~ms}$

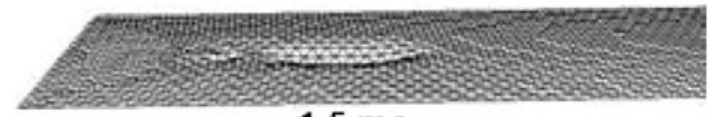

$1.5 \mathrm{~ms}$

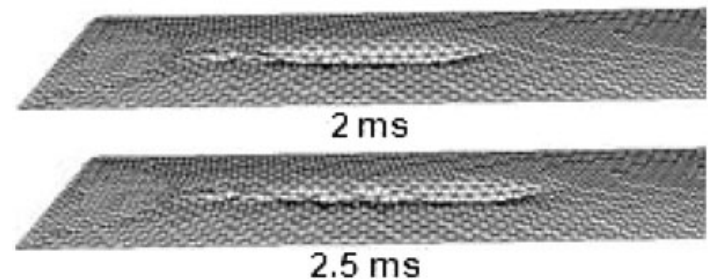

$2.5 \mathrm{~ms}$

Fig. 5 Sequences of free surface deformation

displacement is large compared to the local cell sizes, the cell quality can deteriorate or the cells can become degenerate. This will invalidate the mesh (e.g., result in negative cell volumes) and consequently, will lead to convergence problems when the solution is updated to the next time step. To circumvent this problem, the cells or faces that violate the skewness or size criteria, are agglomerated and are locally remeshed. If the new cells or faces satisfy the skewness criterion, the mesh is locally updated with the new cells (with the solution interpolated from the old cells). Otherwise, the new cells are discarded.

In Fig. 5, we show sequences representing the time evolution of the free surface, and its deformation due to the vaporization during laser beam energy absorption. We note in the sequences the keyhole profile evolution, and its elongated shape due to the relatively high laser beam displacement speed. After a while, a stationary regime is established, and a maximum penetration depth is obtained while the laser beam moves over the sample surface.

Among the results of the performed simulation, we report in Fig. 6 the calculation of the laser absorbed energy distribution, which produces melting and vaporization of matter. The recoil pressure induced by vaporization pushes the metallic liquid generated on keyhole front, to move around the keyhole towards the bulk of the molten pool in the rear region. The vectors velocity distribution represented in Fig. 7 show the direction of the melt around the keyhole.

Figure 8 represents the temperature field distribution from different views. The bird's eye view shows clearly the elongated keyhole and its dimension. Figure 9 represents an 
Fig. 6 Contours of total surface heat flux $\left(\mathrm{W} / \mathrm{m}^{2}\right)$

Fig. 7 Velocity vectors $(\mathrm{m} / \mathrm{s})$ of the metal liquid at a depth of $0.1 \mathrm{~mm}$

Fig. 8 Temperature field distribution
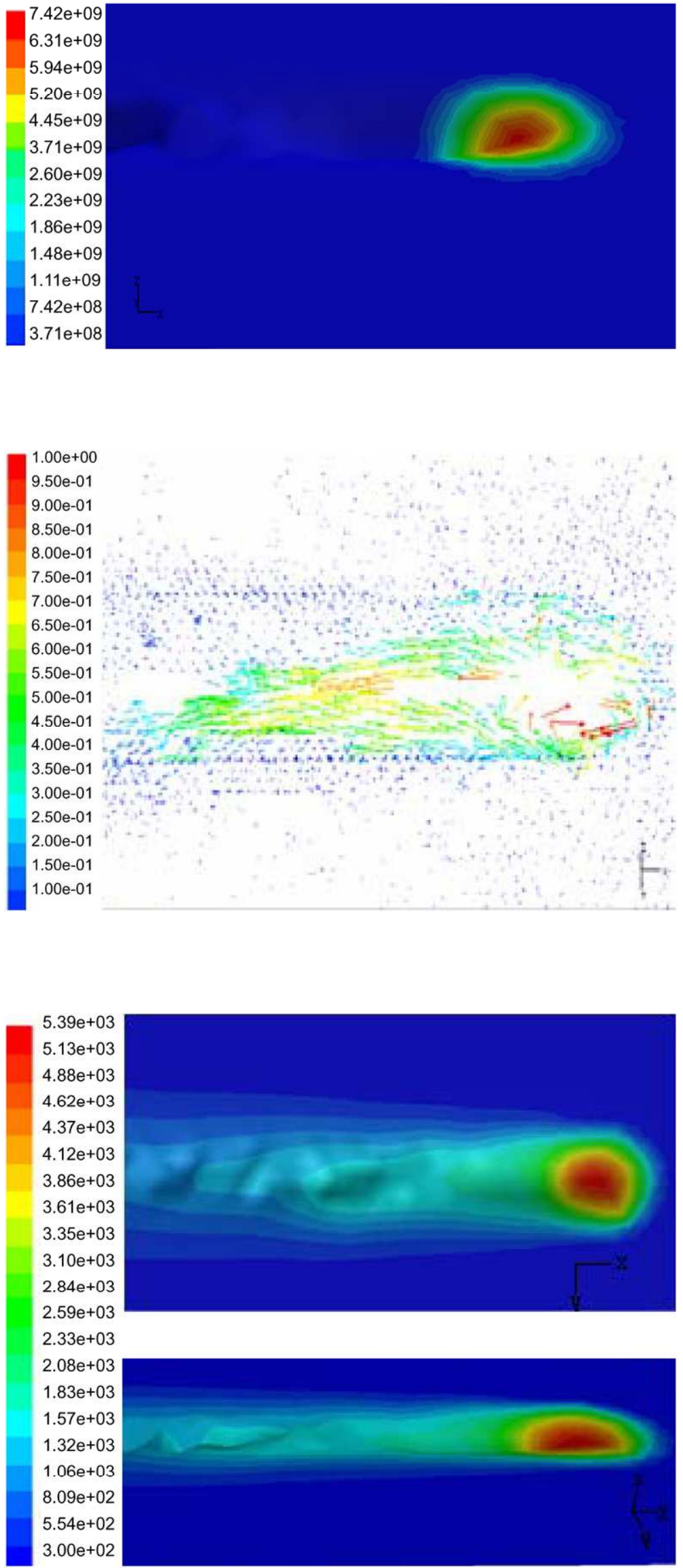


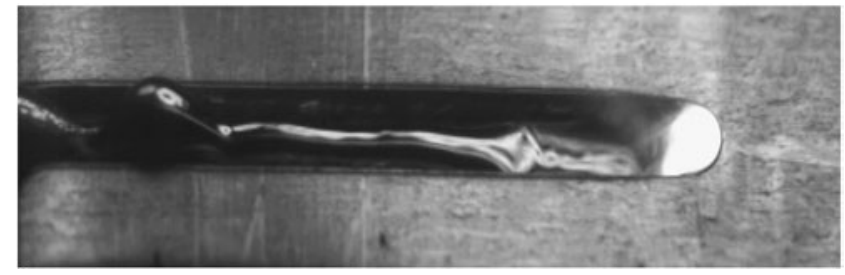

Fig. 9 Experimental observation of humps formation

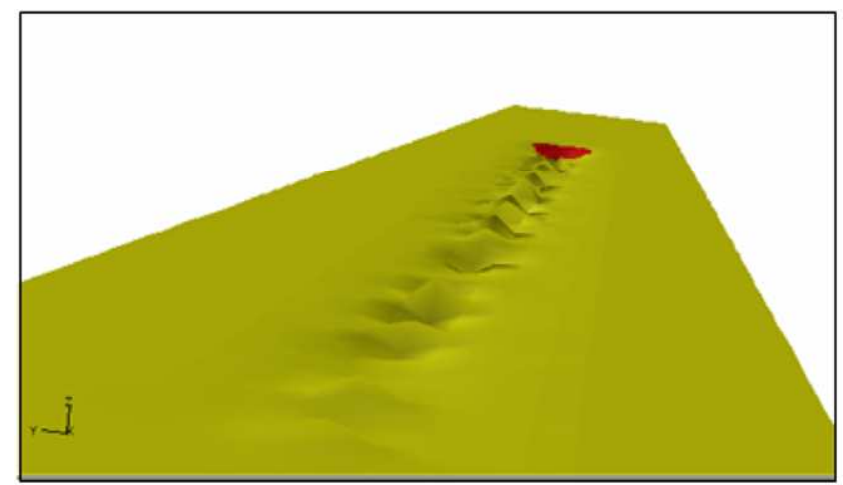

a

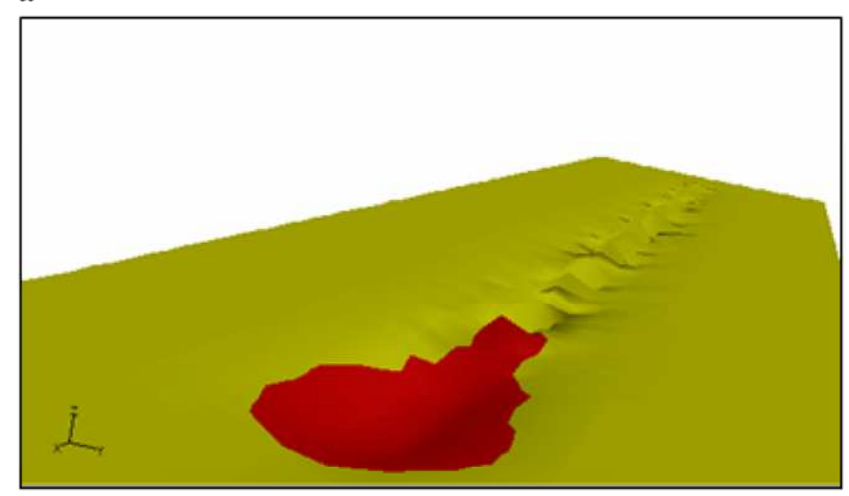

b

Fig. 10 a Sample surface viewed from the rear side; b Sample surface viewed from the molten bath front

experimental result [2] showing clearly an elongated keyhole shape and a hump formation.

From Figs. 8 and 9, one can conclude to some similitude between the experimental observation and the numerical simulation.

Finally, as the main result of our modeling, we present in Figs. 10a and 10b from different angles of observation the sample with the molten bath and the resolidified region. We can see the growth appearing behind the molten bath, which suggests humps formation.

\section{Conclusion}

We have developed a modeling that allowed us to make evident the humps formation at high welding speeds. We have used calculation procedures to insert the main physical mechanisms, the dynamic mesh technique and the specific boundary conditions in the calculation process using a CFD Fluent code.

\section{References}

1. R. Fabbro, S. Slimani, I. Doudet, F. Coste, F. Briand, J. Phys. D: App. Phys. 39, 394-400 (2006)

2. R. Fabbro, S. Slimani, F. Coste, F. Briand, in PICALO 2008 Conf. Proc. (2008), pp. 173-178

3. A. Kumar, T. Debroy, Welding Research (2006), pp. 292s-304s

4. E. Soderstrom, P. Mendez, Sci. Technol. Weld. Join. 11, 572-579 (2006)

5. M.H. Cho, Numerical simulation of arc welding process and its application, Dissertation, The Ohio State University, 2006

6. M.H. Cho, Y.C. Lim, D.F. Farson, Welding Research (2006), pp. $271 \mathrm{~s}-283 \mathrm{~s}$

7. http://www.fluent.com

8. M.I. Tribelsky, Sov. J. Quantum Electron. 8(4), 462-466 (1978)

9. F.V. Bunkin, M.I. Tribel'skii, Sov. Phys. Usp. 32(2), 105-133 (1980)

10. F.V. Bunkin, N.A. Kirichenko, B.S. Luk'yanchuk, Sov. J. Quantum Electron. 11(2), 277-279 (1981)

11. A.A. Samokhin, Sov. J. Quantum Electron. 13(10), 1347-1350 (1983)

12. E.H. Amara, R. Fabbro, J. Phys. D: Appl. Phys. 41(5), 055503 (2008)

13. V. Semak, A. Matsunawa, J. Phys. D: Appl. Phys. 30, 2541-2552 (1997)

14. R. Fabbro, K. Chouf, J. Appl. Phys. 87(9), 4075-4083 (2000)

15. F.D. Cipriani, Etude numérique de la convection thermocapillaire dans un bain fondu créé par laser, Doctorate Thesis de, p. 162, $\mathrm{N}^{\circ}$ 207.91.93, Aix-Marseille II Univ., 1991

16. W.W. Duley, $\mathrm{CO}_{2}$ Lasers: Effects and Applications (Academic Press, New York, 1976)

17. E. Toyerskani, A. Khajepour, S. Corbin, in ICALEO Proc., Scottsdale, Arizona, USA (2002) 